\title{
Trajectories of antidepressant medication use in individuals before and after being granted disability pension due to common mental disorders- a nationwide register-based study
}

\author{
Syed Rahman ${ }^{1 *}$ (D) Michael Wiberg ${ }^{1,5}$, Kristina Alexanderson $^{1}$, Jussi Jokinen ${ }^{2,3}$, Antti Tanskanen ${ }^{2,4}$
} and Ellenor Mittendorfer-Rutz ${ }^{1}$

\begin{abstract}
Background: Early retirement caused by disability pension (DP) due to common mental disorders (CMDs) is frequent in European countries. Inadequate treatment, e.g., suboptimal antidepressant (AD) medication before DP can be crucial in such DP. This explorative study aimed to disentangle trajectories of AD based on defined daily dose (DDD) before and after granted DP, and to characterize the trajectories by socio-demographics and medical factors.

Methods: All 4642 individuals in Sweden aged 19-64 with incident DP due to CMD in 2009-2010 were included. Trajectories of annual DDDs of AD were analysed over a 6-year period by a group-based trajectory method. Associations between socio-demographic or medical factors and different trajectories were estimated by chi ${ }^{2}$-test and multinomial logistic regression.
\end{abstract}

Results: Five trajectories of ADs were identified. Three groups, comprising 34\%, 34\%, and 21\% of the cohort, had constant AD levels before and after DP with mean annual DDDs of 29, 234, and 580, respectively. Two groups, each including $6 \%$ of the cohort, had increasing levels of DDDs, levelling off at around 1150 and 785 DDDs after DP. Particularly age, outpatient care due to mental diagnoses and DP diagnoses were significantly associated with different trajectories $(p<0.05)$. All the groups had a larger proportion of older individuals (> 50\%, 45-64 years), except for the 'increasing low' group, where younger individuals were in majority (>60\%, 18-44 years), who more frequently exited labour market due to 'anxiety disorders', with lower education and more specialised healthcare before DP than the other groups.

Conclusion: The heterogeneity among the five trajectory groups was partly explained by age, the severity of the mental disorder and the DP diagnoses. DDDs of ADs, though on different levels, varied marginally before and after granted DP in the majority. Moreover, AD levels were very low in one third of the individuals. Early identification and focus on the 'increasing low' group might be important in order to identify individuals at risk for further increase in annual DDDs of ADs even after granted DP, and might also contribute in prevention of DP. Further detailed research regarding different groups is warranted.

Keywords: Common mental disorders, Antidepressant, Epidemiology, Psychiatry in Europe, Disability pension, Sick-leave, Group-based trajectories

\footnotetext{
* Correspondence: Syed.Rahman@ki.se

'Department of Clinical Neuroscience, Division of Insurance Medicine,

Karolinska Institutet, SE-171 77 Stockholm, Sweden

Full list of author information is available at the end of the article
} 


\section{Background}

Common mental disorders (CMDs) constitute one of the most frequent reasons for disability pension (DP) claims and rank among the main medical causes of labour market marginalisation in OECD (Organisation for Economic Co-operation and Development) countries [1-6]. CMDs have a strong impact on individuals' lives, e.g., adverse effect on social and occupational functioning [7], potentially leading to long-term sickness absence [8] and consequently even to disability pension [9].

CMDs are known to be positively affected by treatment and rehabilitation efforts and are likely to worsen with inactivity [10-12]. Adequate healthcare before DP, particularly adequate prescription of antidepressants (ADs) can reduce the burden of disease and hereby have an effect on improving work capacity and reducing premature exit from the labour market in terms of DP [13-15]. However, previous studies, which considered cognitive behavioural therapy (CBT), pharmacological treatment, and healthcare visits, have indicated inadequate treatment before being granted DP $[16,17]$.

Recent studies have reported an increase in psychotropic medications before DP due to mental disorders and an immediate decrease after DP [18-20]. It is likely that patterns of such medication may differ for different mental disorders and that such changes might be influenced by different socio-demographic and medical factors. To the best of our knowledge, no study has been conducted yet aiming at identifying potential variability of such trajectories before and after being granted DP and at focussing on one of the most frequent diagnostic DP groups, namely CMDs.

\section{Aim}

The aims of this explorative study were to, among individuals granted DP due to CMD, 1) identify and describe different trajectories of AD over a 6-year period (3 years prior, and 3 years after being granted DP), and 2) analyse the heterogeneity, if any, between the trajectories by characterizing them with regard to socio-demographics and medical factors.

\section{Methods}

\section{Study population}

All individuals aged 19-64 and living in Sweden who were granted DP due to CMD for the first time during 2009-2010 $(N=4642)$ comprised the study base. CMD was defined as 'depressive episode' (F32), 'recurrent depressive disorder' (F33), 'phobic anxiety disorder' (F40), 'other anxiety disorder' (F41), 'obsessive-compulsive disorder' (F42), and 'reaction to severe stress and adjustment disorder' (F43) [21-24], based on the corresponding codes of the International Classification of Diseases (ICD) version 10 [25].
The study population was identified through register linkage at individual level using the unique ten-digit personal number of all residents in Sweden. Information was obtained from the following nationwide registers:

1) Longitudinal integration database for health insurance and labour market studies (LISA) (with information on: sex, age, education, country of birth, type of living area, family situation, and emigration) from Statistics Sweden.

2) (i) National patient register (date and main diagnosis of in- and specialized outpatient care); (ii) Drug register (information on prescribed dispensed drugs, including dates, dosages, amount, Anatomical Therapeutic Chemical (ATC) Classification System code [26], defined daily dose per dispensed pack; and (iii) Cause of death register (date of death) - all three from the National Board of Health and Welfare.

3) Micro-data for analyses of social insurance (MiDAS) (date and main disability pension diagnosis) from the National Social Insurance Agency.

\section{Antidepressants}

Antidepressants were identified based on the respective ATC code (N06A) [26]. Levels of defined daily dose (DDD) of ADs per year during the 3 years before and 3 years after the date of being granted DP were assessed. The DDD, as defined by 'the WHO collaborating centre for Drug Statistics Methodology', is the tentative average maintenance daily dose for a drug, used as main indication in adults [27]. A time scale on an annual basis was introduced where t0 represented the first date of being on DP, $t-1$ to $t-3$ referred to the three respective years prior to DP, and $t+1$ to $t+3$ indicated the 3 years after. The total amount of DDDs for a given year was calculated by summing up the DDDs of any $\mathrm{AD}$ medication during that year. If more than one $\mathrm{AD}$ was purchased during a year, then annual DDDs of all AD were summed up together for that particular year.

\section{Drug purchase subsidies in Sweden}

There is an upper limit of how much an individual has to pay out of pocket for medication during a 12-months period. The limit was between 100 and 126 Euros during the study period $[28,29]$. Individuals can buy for up to a maximum of 3 months of prescribed medication at a time.

\section{Covariates}

Socio-demographics (sex, age, education, country of birth, type of living area, and family situation) were measured on 31-Dec of the year preceding DP granting and categorised as shown in Table 1. Among the medical factors, previous healthcare was measured during the 3 years before starting DP (from t- 3 to t0) and categorized as 'yes' and 'no'. Regarding underlying diagnoses of previous healthcare, F00-F99 (ICD-10) codes were 
categorized as mental and all other as somatic diagnoses. The main DP diagnosis was the main one given when granting the DP $(\mathrm{t} 0)$. We did not consider alteration in the main DP diagnosis, if any, during the study period. Diagnoses were categorized as indicated in Table 1. Annual in- and specialized outpatient healthcare use was considered as a proxy of the severity of the underlying disorder.

\section{Disability pension in Sweden}

All residents in Sweden aged 19-64 years, with a reduced work capacity due to disease or injury, can be granted DP from the Social Insurance Agency, for full$(100 \%)$ or part-time $(75,50$, or $25 \%$ of ordinary working hours) [3]. People aged 19-29 years can be granted temporary DP if their work capacity is reduced due to disease or injury, not only for paid work but also to complete upper-secondary education, and individuals between 30 and 64 years of age can be granted permanent DP [3].

\section{Statistical analyses}

We calculated the individual annual DDDs for each specific $\mathrm{AD}$ for the six studied years, considering the date of granted DP; t0. Then we summed up DDDs of all specific ADs the individual bought during a one-year interval. Annual cumulative DDDs exceeding 1500 (around 4 DDDs) were deemed unusual (might be due to special cases, large purchases before traveling abroad, or error in data). So any such annual DDDs were truncated at a level of 1500 (equals 194 yearly purchases).

Thereafter, we used group-based trajectory modelling to estimate trajectories of $\mathrm{AD}$ among individuals with incident DP due to CMD during 2009-2010, for six time points (i.e. within a six-year window, starting from 3 years before and ending at 3 years after the date being granted DP). These models estimate changes in AD patterns over time in multiple subgroups within the cohort and estimate a regression model for each discrete group, and assess proportions of individuals in each group.

Additionally, this flexible model allows for different polynomials of the outcome [30]. We used the Bayesian information criterion (BIC) to test the best-fitted model related to the number of groups between 2 to 8 , and in parallel, we also considered the proportions of the individuals in each group. While six and seven group models had better BIC values compared to the five-group model, there were very few individuals in some of the groups. Therefore, the model with five groups was considered most appropriate.

Probabilities for an individual to be assigned to a specific trajectory group were calculated. The highest estimated probability was used to decide each individual's group belonging. Côté et al. recommend that the average probability for individuals of a trajectory group should be $\geq 0.70$ [31]. Such average probability for individuals of our cohort was 0.89 , indicating a very good fit. It should be noted that all the time points represented an interval of 1 year calculated on the basis of DP granting date ( $\mathrm{t} 0)$, but for the sake of graphical presentation, $\mathrm{t} 0$ was calculated as the average of $t-1$ and $t+1$, though $t 0$ represented a date and not an interval (Fig. 1).

We calculated descriptive statistics of the sociodemographics and medical factors prior to DP, after assessing potential sex differences in these factors by chi $^{2}$-test. We then estimated their associations in each $\mathrm{AD}$ trajectory group by $\mathrm{chi}^{2}$-test and multinomial logistic regression. The likelihood ratio tests were used to evaluate whether socio-demographic and medical factors were associated with type of trajectory group in the full model. Moreover, Nagelkerke pseudo $\mathrm{R}^{2}$ values were estimated to evaluate the strength of these associations. By consecutively excluding and re-including each factor from the full model, we calculated differences in $\mathrm{R}^{2}$ for each factor in order to examine the contribution of a given factor to the full model.

Analyses were carried out for the entire study population with DP due to CMD regardless of grade (part-time/ full-time) as sensitivity analyses revealed no differences in the trajectories between individuals with full-time and part-time DP.

In case of death or emigration during the study period, due to differences in the exposure time, the data on DDDs for an individual was considered as missing for the whole year of the event and onward.

Data processing was performed using statistical software SAS for Windows version 9.4 (SAS-based procedure "Traj" [32]) and SPSS for Windows version $22.0\left(\mathrm{chi}^{2}\right.$-test and multinomial logistic regression).

\section{Results}

In Table 1, descriptive statistics, including sociodemographics and medical factors for the cohort (individuals with incident DP due to CMD in 2009-2010) are presented. Two thirds of the cohort were women (62.4\%) and $77.3 \%$ were born in Sweden. When granted DP, most of them were aged 45-64 years (57.8\%), had proceeded to high school education (46.0\%), lived in big cities (39.9\%), and were single without any child at home (45.3\%). A higher proportion of the women (14.5\%) than of the men $(3.3 \%)$ were single with children living at home. Depressive disorders were the most common (46.3\%) DP diagnosis. A history of specialised outpatient care was more common than inpatient care due to mental or somatic diagnoses $(57.6 \%, 74.0 \%$ compared to $16.7 \%, 29.1 \%$, respectively).

Figure 1 shows the estimated five groups of different trajectories of $\mathrm{AD}$. The groups were labelled as, 'low 
Table 1 Descriptive statistics for all women $(n=2897)$ and men $(n=1745)$ granted disability pension (DP) due to common mental disorders in 2009-2010 in Sweden ( $N=4642)$

\begin{tabular}{|c|c|c|c|c|c|c|}
\hline \multirow[t]{2}{*}{ Characteristics, measured at the end of the year preceding granted DP } & \multicolumn{2}{|l|}{ All } & \multicolumn{2}{|l|}{ Women } & \multicolumn{2}{|l|}{ Men } \\
\hline & n 4642 & $\% 100$ & $n 2897$ & $\% 62.4$ & $n 1745$ & $\% 37.6$ \\
\hline \multicolumn{7}{|l|}{ Socio-demographic characteristics ${ }^{b}$} \\
\hline \multicolumn{7}{|l|}{$\mathrm{Age}^{\mathrm{a}}$} \\
\hline $18-24$ & 837 & 18.0 & 520 & 17.9 & 317 & 18.2 \\
\hline $25-34$ & 490 & 10.6 & 294 & 10.1 & 196 & 11.2 \\
\hline $35-44$ & 635 & 13.7 & 407 & 14.0 & 228 & 13.1 \\
\hline $45-54$ & 1112 & 24.0 & 730 & 25.2 & 382 & 21.9 \\
\hline $55-64$ & 1568 & 33.8 & 946 & 32.7 & 622 & 35.6 \\
\hline \multicolumn{7}{|l|}{ Education (years) ${ }^{a}$} \\
\hline Compulsory ( $\leq 9)$ & 1301 & 28.0 & 710 & 24.5 & 591 & 33.9 \\
\hline High school (10-12) & 2134 & 46.0 & 1353 & 46.7 & 781 & 44.8 \\
\hline University (> 12) & 1207 & 26.0 & 834 & 28.8 & 373 & 21.4 \\
\hline \multicolumn{7}{|l|}{ Country of birth ${ }^{a}$} \\
\hline Sweden & 3589 & 77.3 & 2314 & 79.9 & 1275 & 73.1 \\
\hline Other EU countries & 278 & 6.0 & 180 & 6.2 & 98 & 5.6 \\
\hline Rest of the world & 775 & 16.7 & 403 & 13.9 & 372 & 21.3 \\
\hline \multicolumn{7}{|l|}{ Type of living area ${ }^{a c}$} \\
\hline Big cities & 1852 & 39.9 & 1120 & 38.7 & 732 & 41.9 \\
\hline Medium sized cities & 1576 & 34.0 & 988 & 34.1 & 588 & 33.7 \\
\hline Small towns/villages & 1214 & 26.2 & 789 & 27.2 & 425 & 24.4 \\
\hline \multicolumn{7}{|l|}{ Family situation $^{a}$} \\
\hline Married ${ }^{d}$ living without children & 743 & 16.0 & 496 & 17.1 & 247 & 14.2 \\
\hline Married ${ }^{d}$ living with children & 967 & 20.8 & 598 & 20.6 & 369 & 21.1 \\
\hline Single $e^{e}$ living without children & 2103 & 45.3 & 1188 & 41.0 & 915 & 52.4 \\
\hline Single living with children & 478 & 10.3 & 420 & 14.5 & 58 & 3.3 \\
\hline Adolescents living with parents, $<20$ years & 351 & 7.6 & 195 & 6.7 & 156 & 8.9 \\
\hline \multicolumn{7}{|l|}{ Medical characteristics } \\
\hline \multicolumn{7}{|l|}{ Main DP diagnosis ${ }^{a}$} \\
\hline Depressive disorders & 2150 & 46.3 & 1305 & 45.0 & 845 & 48.4 \\
\hline Anxiety disorders & 1441 & 31.0 & 867 & 29.9 & 574 & 32.9 \\
\hline Stress-related mental disorders & 1051 & 22.6 & 725 & 25.0 & 326 & 18.7 \\
\hline \multicolumn{7}{|l|}{ Previous healthcare $^{f}$} \\
\hline Mental inpatient care ${ }^{a}$ & 777 & 16.7 & 460 & 15.9 & 317 & 18.2 \\
\hline Specialized mental outpatient care ${ }^{a}$ & 2674 & 57.6 & 1588 & 54.8 & 1086 & 62.2 \\
\hline Somatic inpatient care & 1349 & 29.1 & 864 & 29.8 & 485 & 27.8 \\
\hline Specialized somatic outpatient care ${ }^{a}$ & 3436 & 74.0 & 2225 & 76.8 & 1211 & 69.4 \\
\hline
\end{tabular}

${ }^{a}$ Significant sex differences

${ }^{\mathrm{b}}$ All socio-demographic variables are measured at to

'Type of living area: big cities (Stockholm, Gothenburg and Malmö); medium sized cities (cities with more than 90,000 inhabitants within 30 km distance from the centre of the city); small cities/villages/rural

${ }^{\mathrm{d}}$ Married includes all living with partner; cohabitant

esingle includes divorced, separated, or widowed

fMeasured during t-3 to to

constant,' 'low increasing,' 'middle constant,' 'high constant', and 'high increasing'. Many of the individuals ('low constant' $33.5 \%$ of the cohort) had none or very low (less than 50) annual DDDs of AD. Nearly 6\% percent ('low increasing') had very low annual DDDs 3 years before DP granting, and showed a steep increase 


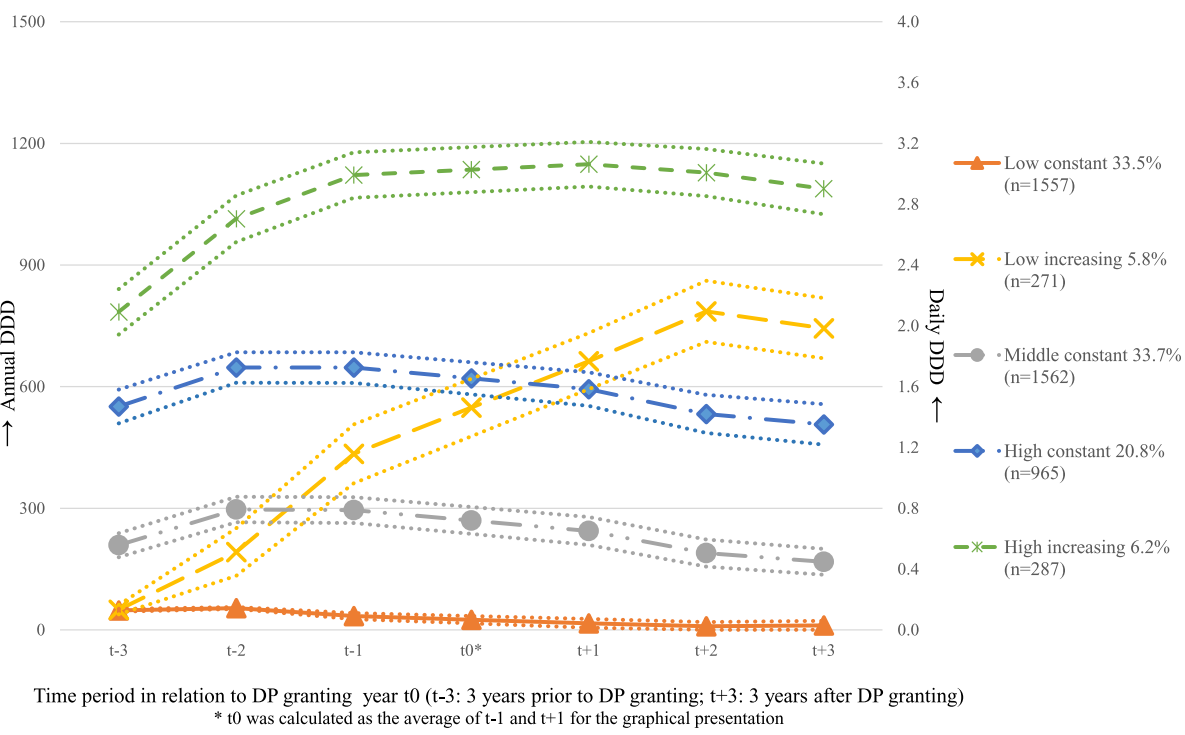

Fig. 1 Trajectory groups of antidepressants according to annual defined daily doses (DDDs) and percentages of individuals with granted disability pension (DP) due to common mental disorders granted in 2009-2010 ( $N=4642)$ within each trajectory group in Sweden. (The dotted lines represent $95 \%$ confidence intervals)

in annual DDDs of AD up to 785 up until 2 years following DP. The group 'middle constant' (33.7\%) had annual DDDs in between 200 and 300 during the study period. The group 'high constant' included $20.8 \%$ of the cohort, and had 500-600 DDDs per year throughout the study period. In the groups 'middle constant' and 'high constant', there was a slight decline in DDDs of AD following the DP. Six percent of the cohort had over 1000 DDDs per year since 2 years before DP granting until the end of follow-up (high increasing).

Table 2 describes the distribution of the sociodemographics and medical factors across the five identified trajectory groups. All socio-demographic and medical factors, but sex and previous healthcare due to somatic diagnoses, were significantly associated with different trajectory groups $(p<0.05)$ in the unadjusted analyses. In the full model, along with other variables, sex was significantly associated with the trajectory groups. The full model explained $17.2 \%$ of the variance between the groups (using Nagelkerke pseudo $R^{2}$ ). The highest estimated difference of $5 \%$ was observed for 'Previous mental outpatient care' (diff. in $R^{2}=0.05$ ), otherwise the individual factors, other than age and main DP diagnosis (diff. in $\mathrm{R}^{2}=0.02$ ), merely effected the full model independently.

All the groups had a larger proportion of older individuals (> 50\%, 45-64 years), except for the 'low increasing', where younger individuals constituted the absolute majority ( $>60 \%, 18-44$ years), and notably $41.3 \%$ of those in this group were in the 18-24 age range. This group also had fewer individuals (17.3\%) who have been to university compared to the other groups, whereas the "high increasing' group had the highest proportions of individuals having attended high school or university (53.0\% and $29.6 \%$, respectively). In the 'low increasing' group, $80 \%$ of the individuals were single and did not have any children. Other socio-demographic factors were fairly equally distributed among all five groups.

Regarding the main DP diagnosis, the 'low increasing' group had equal proportions of depressive and anxiety disorders $(43.2 \%$ each), whereas in all other trajectory groups, depressive disorders dominated. The percentage of the individuals with 'stress-related mental disorders' as main DP diagnosis was largest in the 'low constant' (31.5\%) and followed by the 'middle constant' (21.0\%) groups. The proportions of the individuals from the 'high increasing' group who had had previous in- or specialized outpatient care due to mental diagnoses were approximately twice as high compared to the proportions of the 'low constant' group (24.0\%, 79.4\% and 9.1\%, 40.5\%, respectively).

Approximately $41 \%(n=1906)$ of the study population did not receive in- or specialized psychiatric care during the 3 years prior to DP grant. Further analyses showed that this group consisted individuals somewhat older (mean age 49 vs 44 years), with better educational level (university education: $32 \%$ vs $26 \%$ ) than the whole study population (data not shown). Regarding the main DP diagnosis, more individuals without previous psychiatric specialised health care were granted DP due to stressrelated mental disorders than in the whole study population (31.8\% vs $22.6 \%$ ), and fewer received DP due to anxiety disorders (22.5\% vs $31 \%$ ) (data not shown). Trajectory analyses revealed this group had similar patterns of trajectory groups, but larger proportions of 'low constant' and 'high constant' group (38.5\% vs 33.5\%, 
Table 2 Distributions and associations of socio-demographic and medical characteristics in each trajectory group of antidepressants according to annual defined daily doses (DDDs), in individuals with disability pension (DP) due to common mental disorders granted in 2009-2010 ( $N=4642)$ in Sweden

\begin{tabular}{|c|c|c|c|c|c|c|c|c|}
\hline \multirow[t]{2}{*}{ Characteristics } & \multirow{2}{*}{$\begin{array}{l}\text { Low constant } \\
n(\%) \\
1557(33.54)\end{array}$} & \multirow{2}{*}{$\begin{array}{l}\text { Low increasing } \\
n(\%) \\
271(5.84)\end{array}$} & \multirow{2}{*}{$\begin{array}{l}\text { Middle constant } \\
n(\%) \\
1562(33.65)\end{array}$} & \multirow{2}{*}{$\begin{array}{l}\text { High constant } \\
n(\%) \\
965(20.79)\end{array}$} & \multirow{2}{*}{$\begin{array}{l}\text { High increasing } \\
n(\%) \\
287(6.18)\end{array}$} & \multirow{2}{*}{$\begin{array}{l}\text { Pearson's } \\
\text { Chi-Square } \\
(p \text {-value })^{f}\end{array}$} & \multirow{2}{*}{$\begin{array}{l}\text { Log-likelihood test } \\
\text { Chi-Square } \\
(p \text {-value })^{9}\end{array}$} & \multirow[t]{2}{*}{ Diff. in $\mathrm{R}^{2 *}$} \\
\hline & & & & & & & & \\
\hline \multicolumn{9}{|l|}{ Socio-demographic characteristics } \\
\hline \multicolumn{9}{|l|}{$\operatorname{Sex}^{\mathrm{a}}$} \\
\hline Men & $604(38.8)$ & $102(37.6)$ & $598(38.3)$ & $347(36.0)$ & $94(32.8)$ & $5.2(0.26)$ & $10.7(0.03)$ & 0.002 \\
\hline Women & $953(61.2)$ & $169(62.4)$ & $964(61.7)$ & $618(64.0)$ & $193(67.2)$ & & & \\
\hline \multicolumn{9}{|l|}{$\mathrm{Age}^{\mathrm{a}}$} \\
\hline $18-24$ & $286(18.4)$ & $112(41.3)$ & 305 (19.5) & $101(10.5)$ & $33(11.5)$ & $207.4(<0.001)$ & $109.1(<0.001)$ & 0.021 \\
\hline $25-34$ & $135(8.7)$ & $44(16.2)$ & $172(11.0)$ & $104(10.8)$ & $35(12.2)$ & & & \\
\hline $35-44$ & $202(13.0)$ & $23(8.5)$ & $207(13.3)$ & $144(14.9)$ & $59(20.6)$ & & & \\
\hline $45-54$ & $348(22.4)$ & $42(15.5)$ & $360(23.0)$ & $277(28.7)$ & 85 (29.6) & & & \\
\hline $55-64$ & $586(37.6)$ & $50(18.5)$ & $518(33.2)$ & $339(35.1)$ & $75(26.1)$ & & & \\
\hline \multicolumn{9}{|l|}{ Education $\left(\right.$ years) $^{a}$} \\
\hline Compulsory $(\leq 9)$ & $495(31.8)$ & $114(42.1)$ & $444(28.4)$ & $198(20.5)$ & $50(17.4)$ & $88.3(<0.001)$ & $29.7(<0.001)$ & 0.006 \\
\hline High school (10-12) & $649(41.7)$ & $110(40.6)$ & $738(47.2)$ & $485(50.3)$ & $152(53.0)$ & & & \\
\hline University (> 12) & $413(26.5)$ & $47(17.3)$ & $380(24.3)$ & $282(29.2)$ & $85(29.6)$ & & & \\
\hline \multicolumn{9}{|l|}{ Country of birth ${ }^{a}$} \\
\hline Sweden & $1171(75.2)$ & $219(80.8)$ & $1162(74.4)$ & $792(82.1)$ & $245(85.4)$ & $40.8(<0.001)$ & $57.3(<0.001)$ & 0.011 \\
\hline Other EU25 countries & $106(6.8)$ & $12(4.4)$ & $95(6.1)$ & $55(5.7)$ & $10(3.5)$ & & & \\
\hline Rest of the world & $280(18.0)$ & $40(14.8)$ & $305(19.5)$ & $118(12.2)$ & $32(11.1)$ & & & \\
\hline \multicolumn{9}{|l|}{ Type of living area } \\
\hline Big cities & $683(43.9)$ & $97(35.8)$ & $586(37.5)$ & $375(38.9)$ & $111(38.7)$ & $21.9(<0.01)$ & $20.6(<0.01)$ & 0.004 \\
\hline Medium sized cities & $485(31.1)$ & $95(35.1)$ & $553(35.4)$ & $353(36.6)$ & $90(31.4)$ & & & \\
\hline Small towns/villages & $389(25.0)$ & $79(29.2)$ & $423(27.1)$ & $237(24.6)$ & $86(30.0)$ & & & \\
\hline \multicolumn{9}{|l|}{ Family situation ${ }^{a}$} \\
\hline $\begin{array}{l}\text { Married living } \\
\text { without children }\end{array}$ & $250(16.1)$ & $32(11.8)$ & $248(15.9)$ & $168(17.4)$ & $45(15.7)$ & $91.9(<0.001)$ & $27.1(0.04)$ & 0.005 \\
\hline $\begin{array}{l}\text { Married living } \\
\text { with children }\end{array}$ & $311(20.0)$ & $30(11.1)$ & $324(20.7)$ & $233(24.1)$ & $69(24.0)$ & & & \\
\hline $\begin{array}{l}\text { Singled living } \\
\text { without children }\end{array}$ & $697(44.8)$ & $136(50.2)$ & $718(46.0)$ & $415(43.0)$ & $137(47.7)$ & & & \\
\hline $\begin{array}{l}\text { Single }{ }^{d} \text { living } \\
\text { with children }\end{array}$ & $164(10.5)$ & $23(8.5)$ & $160(10.2)$ & $106(11.0)$ & $25(8.7)$ & & & \\
\hline $\begin{array}{l}\text { Adolescents living } \\
\text { with parents, }<20 \text { years }\end{array}$ & $135(8.7)$ & $50(18.5)$ & $112(7.2)$ & $43(4.5)$ & $11(3.8)$ & & & \\
\hline \multicolumn{9}{|l|}{ Medical characteristics } \\
\hline \multicolumn{9}{|l|}{ Main DP diagnosis ${ }^{a}$} \\
\hline Depressive disorders & $630(40.5)$ & $117(43.2)$ & $727(46.5)$ & $521(54.0)$ & $155(54.0)$ & $140.7(<0.001)$ & $75.5(<0.001)$ & 0.015 \\
\hline Anxiety disorders & $436(28.0)$ & $117(43.2)$ & $507(32.5)$ & $290(30.1)$ & $91(31.7)$ & & & \\
\hline $\begin{array}{l}\text { Stress-related mental } \\
\text { disorders }\end{array}$ & $491(31.5)$ & $37(13.7)$ & $328(21.0)$ & $154(16.0)$ & $41(14.3)$ & & & \\
\hline \multicolumn{9}{|l|}{$\begin{array}{l}\text { Previous mental } \\
\text { inpatient care }\end{array}$} \\
\hline Yes & $142(9.1)$ & $63(23.2)$ & $274(17.5)$ & $229(23.7)$ & $69(24.0)$ & $118.6(<0.001)$ & $31.5(<0.001)$ & 0.006 \\
\hline No & $1415(90.9)$ & $208(76.8)$ & $1288(82.5)$ & $736(76.3)$ & $218(76.0)$ & & & \\
\hline \multicolumn{9}{|l|}{$\begin{array}{l}\text { Previous mental specialized } \\
\text { outpatient care }\end{array}$} \\
\hline Yes & $630(40.5)$ & $183(67.5)$ & $942(60.3)$ & 691 (71.6) & $228(79.4)$ & $336.5(<0.001)$ & $244.7(<0.001)$ & 0.048 \\
\hline
\end{tabular}


Table 2 Distributions and associations of socio-demographic and medical characteristics in each trajectory group of antidepressants according to annual defined daily doses (DDDs), in individuals with disability pension (DP) due to common mental disorders granted in 2009-2010 ( $N=4642)$ in Sweden (Continued)

\begin{tabular}{|c|c|c|c|c|c|c|c|c|}
\hline Characteristics & $\begin{array}{l}\text { Low constant } \\
n(\%) \\
1557(33.54)\end{array}$ & $\begin{array}{l}\text { Low increasing } \\
n(\%) \\
271(5.84)\end{array}$ & $\begin{array}{l}\text { Middle constant } \\
n(\%) \\
1562(33.65)\end{array}$ & $\begin{array}{l}\text { High constant } \\
n(\%) \\
965(20.79)\end{array}$ & $\begin{array}{l}\text { High increasing } \\
n(\%) \\
287(6.18)\end{array}$ & $\begin{array}{l}\text { Pearson's } \\
\text { Chi-Square } \\
(p \text {-value })^{f}\end{array}$ & $\begin{array}{l}\text { Log-likelihood test } \\
\text { Chi-Square } \\
(p \text {-value })^{g}\end{array}$ & Diff. in $R^{2 *}$ \\
\hline No & $927(59.5)$ & $88(32.5)$ & $620(39.7)$ & $274(28.4)$ & 59 (20.6) & & & \\
\hline \multicolumn{9}{|l|}{$\begin{array}{l}\text { Previous somatic } \\
\text { inpatient care }\end{array}$} \\
\hline Yes & $416(26.7)$ & $90(33.2)$ & $458(29.3)$ & $299(31.0)$ & $86(30.0)$ & $8.3(0.08)$ & $4.5(0.4)$ & 0.001 \\
\hline No & 1141 (73.3) & $181(66.8)$ & 1104 (70.7) & $666(69.0)$ & $201(70.0)$ & & & \\
\hline \multicolumn{9}{|c|}{$\begin{array}{l}\text { Previous somatic specialized } \\
\text { outpatient care }{ }^{\mathrm{e}}\end{array}$} \\
\hline Yes & $1153(74.1)$ & $203(74.5)$ & $1144(73.2)$ & $723(74.9)$ & $213(74.2)$ & $1.02(0.91)$ & $1.7(0.8)$ & 0.000 \\
\hline No & 404 (25.9) & $68(25.1)$ & $418(26.8)$ & $242(25.1)$ & $74(25.8)$ & & & \\
\hline \multicolumn{9}{|l|}{$\begin{array}{l}{ }^{*} \text { Difference in Nagelkerke } \mathrm{p} \\
\text { is } 0.172 \\
{ }^{\mathrm{a}} \text { Measured at to } \\
{ }^{\mathrm{b}} \text { Type of living area: big citi } \\
\text { the centre of the city; small } \\
{ }^{\mathrm{c}} \text { Married includes all living } \\
{ }^{\mathrm{d}} \text { Single includes divorced, } \mathrm{s} \\
{ }^{\mathrm{e}} \text { Measured during } \mathrm{t}-3 \text { to t0 } \\
{ }^{\mathrm{f}} \text { Crude model } \\
{ }^{\mathrm{g}} \text { Mutually adjusted model }\end{array}$} \\
\hline
\end{tabular}

and $24.3 \%$ vs $20.8 \%$, respectively) and smaller proportions of 'middle constant' trajectory groups $(24.1 \%$ vs 33.7\%), and received lower levels of ADs. Multinomial regression suggested similar associations of covariates with trajectory groups as in the whole study population (data not shown).

\section{Discussion}

\section{Main findings}

In this explorative study, we identified five different trajectories of DDDs of ADs over a 6-year period among all 4642 individuals granted DP due to CMDs during 2009-2010. For the vast majority of individuals (89\%), DDDs of ADs - though on different levels - varied only slightly before and after granting of a DP. Out of them about a third of the individuals, who more often had stress-related DP diagnoses and less psychiatric care, received very low levels or no ADs during the years around the time of DP grant. Two smaller groups $(6 \%$ each) registersshowed increases of DDDs up to granting of the DP, in one group DDDs levelled off afterwards and in the other group they kept increasing. Individuals in this latter group tended to be younger and were more likely to have an anxiety disorder as a DP diagnosis.

\section{Methodological considerations}

To the best of our knowledge, this is the first study attempting to disentangle different groups of trajectories related to the amount of ADs during the years before and after being granted DP due to CMD. Previous studies have not discriminated between specific DP mental diagnoses and have used other statistical methods, which are not capable to identify groups with varying trajectories $[18,19]$.

Main strengths of this study include the use of high quality population-based nationwide registers [33-37] with longitudinal data linked at individual level. Further strengths result from the use of a large study group which comprised all individuals aged 18-64 from whole Sweden who were granted DP due to CMD during the studied exposure years (2009-2010). This means the study is not merely based on a sample. The register data also means that the study was not affected by recall bias regarding exposure and outcome measures. Moreover, there was no loss to follow up and DP diagnoses were set by the treating and certifying physician through thorough assessments of the patients' disease, functioning, and work incapacity. An additional advantage is that a wide range of socio-demographic and medical factors could be included as potential confounders. Another important strength of our study is that a potential social gradient for $\mathrm{AD}$ purchase can be considered negligible. First, drug purchase is considerably subsidised in Sweden and the level of these subsidies did not change much during study period. Moreover, analyses were controlled for socio-economic factors.

Regarding limitations, the validity of sick-leave and DP diagnoses is often discussed; however, few related studies are carried out so far. A Swedish study from 1991 concluded that sick-leave diagnoses have high validity when compared to the diagnoses from medical records [38]. Additionally, granting of DP is preceded by a long 
process of medical evaluation and work-capacity assessments [3]. Moreover, due to the stigma around mental diagnoses $[39,40]$, we assume that a mental diagnosis is given as a main DP diagnosis only when the patient actually has a mental disorder and when the main reason of work disability cannot be attributed to a somatic diagnosis [41]. On the other hand, this implies that some people with CMD might not have been given CMD as the main DP diagnosis on the DP certificate. Thus, they would not be included in this study. This can also be seen as a strength, as our cohort of individuals with DP due to CMD is more strictly defined. Another limitation is that, as in all studies using drug registers, we have no information on whether the individual actually used the dispensed AD. However, as the AD cannot be prescribed for more than 3 months at a time, it is plausible that the patient would not repeatedly have bought medication not used.

A point to be noted is, that we did not have the possibility to measure formally the severity of CMD, we have rather used information on in- or specialized outpatient healthcare use as a proxy of severity. Concerning the possibility of returning to work after DP granting, it should be noted that DP is a permanent measure for individuals aging from 30 to 64 years (around $75 \%$ of the study population). Moreover, as we have considered only the individuals who were on DP during the whole follow-up, it is unlikely for even the younger individuals (with temporal DP) to have returned to work. However, we do not have the information if some have returned to work after the follow-up period. Also, looking at the role of employers would have given further insight, but unfortunately, we do not have data on different aspects of employers.

\section{Discussions of findings}

The study revealed heterogeneity between the five groups identified based on the amounts of ADs. A third of the individuals in our study population had either no or very low annual DDDs of ADs during the 6 years of observation. This finding is surprising and may suggest that there is a possibility that these individuals might not have received optimal pharmacological treatment by ADs before being granted DP, which is in line with previous reports [16]. On the other hand, the individuals, if treated without pharmacotherapy, e.g., psychotherapy only, or other occupational therapy during some years of observation and later with ADs, might show low DDDs during the study period. Moreover, some in the cohort were prescribed other psychotropic drugs than ADs. Around $8-11 \%$ (depending upon the trajectory group) of the individuals in this cohort were prescribed anxiolytics or sedatives, separately or along with $\mathrm{AD}$ (data not shown). There is also a possibility of poor compliance to ADs due to their potential side effects, e.g., weight gain, decreased libido, diarrhoea, agitation etc. [42-44], which might have led to low annual DDDs. Finally, one should also consider that individuals might have improved clinically through $\mathrm{AD}$ treatment, but not regarding their work capacity [45-47].

Our analyses showed that most trajectory groups had relatively stable annual DDDs of $\mathrm{AD}$ around the time when granted DP. This is in contrast to findings from a Finnish project, where use of AD substantially increased before and decreased immediately after granted DP, especially among those with a mental DP diagnosis $[18,19]$. These discrepancies in findings might arise from the differences in DP diagnoses, i.e. in our study the focus was on CMDs, while other previous studies included all mental disorders. One group differed considerably from the patterns of the other trajectory groups, i.e., the "low increasing' group which showed a steep increase in DDDs of $\mathrm{AD}$ since the beginning of the study period ( $t-3)$ up to DP granting and continued to increase after that.

The study findings also indicate heterogeneity regarding socio-demographics and medical factors between the trajectory groups. Among the socio-demographic variables, age had the strongest association with trajectory groups in the full model. There were also observable differences in educational level and family situation between the trajectory groups. Differences in educational level or in the family status in the 'low increasing' trajectory group might have been due to the younger age distribution in that group. Regarding the level of education, individuals with higher educational level are likely to have more employment security regarding a current job, or even a greater choice of alternative jobs if they are not able to remain at the present one due to health reasons [48]. It is further not unlikely that these individuals may remain longer time at work with a later pensionary age despite a higher clinical severity and higher $\mathrm{AD}$ doses than their low educated peers.

Depressive disorders were the most common DP diagnosis in all the trajectory groups. However, anxiety disorders contributed equally much in the 'low increasing' group. This may be because many of them were young, and anxiety disorders usually have an earlier onset and they are detected earlier in life [49-51]. Previous mental inpatient or specialized outpatient healthcare was proportionate to the amount of $\mathrm{AD}$, i.e., the highest $\mathrm{AD}$ purchases were found in the constant 'high group' and the lowest in the 'low constant' group. It might be necessary to pay special attention to the 'low increasing' group because they also had a high use of previous mental healthcare. As this includes the youngest among all trajectory groups, we expected that they would less frequently be using healthcare $[52,53]$. Thus, our results suggest that individuals belonging to this group might have suffered from severe mental disorders several years 
before granted DP, and that the disorders worsened with time leading to DP. Notably, this group also had the highest level of previous somatic inpatient care. Such high use of previous healthcare suggests that further research should also focus on somatic comorbidity. On the other hand, $20-60 \%$ of the individuals, depending on the trajectory groups, did not receive any specialized mental healthcare during 3 years prior to DP. This is not in accordance with the Swedish sick-leave guidelines [54], stating that all patients on sickness absence due to depression for more than 6 months, should be referred to a specialist. This may indicate that these individuals might have not received optimal treatment during the pre-DP years, leading to further worsening of work capacity and later resulting in exclusion from the labour market by being granted DP [16].

A large proportion of the study population (41\%), who were more often granted DP due to stress-related mental disorders, did not receive psychiatric in- or specialized outpatient care during the 3 years before being granted DP. This is consistent with previous research suggesting that individuals with work disability due to stress-related mental disorders have a lower proportion of specialized health care than individuals with other common mental disorders e.g., depressive disorders [55].

\section{Conclusion}

The study identified five different groups according to the annual DDDs of ADs among individuals granted DP due to CMD. The five groups were heterogeneous regarding socio-demographics and medical factors, particularly regarding age, the severity of the mental disorder and the $\mathrm{DP}$ diagnoses. In the majority of the individuals within a trajectory group, the levels of DDDs of ADs varied only marginally before and after being granted DP. The study also posts a query regarding optimal pharmacological treatment for CMD during the pre-DP years, which in turn may contribute in prevention of premature exit from the labour market due to common mental disorders.

\section{Abbreviations \\ AD: Antidepressant; ATC: Anatomical therapeutic chemical; BIC: Bayesian information criterion; CMD: Common mental disorder; DDD: Defined daily dose; DP: Disability pension; ICD: International classification of diseases; LISA: Longitudinal integration database for health insurance and labour market studies; MiDAS: Micro-data for analyses of social insurance; OECD: Organisation for Economic Co-operation and Development}

\section{Acknowledgements}

Not applicable.

\section{Funding}

Swedish Research Council for Health, Working Life and Welfare, the Swedish Research Council (Project numbers: K2009-61P-21304-04-4; K2009-61X-21305-01-1; K2011-80P-21782-01-4), and the Karolinska Institutet's funding for doctoral students.

\section{Availability of data and materials}

The datasets generated and analysed during the current study are not publicly available due to the privacy act. According to the Swedish Ethical Review Act, the Personal Data Act, and the Administrative Procedure Act, data can only be made available, after legal review, for researchers who meet the criteria for access to this type of sensitive and confidential data. Readers may contact Professor Kristina Alexanderson

(kristina.alexanderson@ki.se) regarding questions about this.

\section{Authors' contributions}

SR- planning, data management and analyses, interpreting results and writing. MW- data management and analyses, interpreting results and writing. KA- planning, interpreting results and writing. JJ- planning, interpreting results and writing. AT- planning, interpreting results and writing. EM- planning, interpreting results and writing. All authors read and approved the final manuscript.

\section{Ethics approval and consent to participate}

The study population was identified by linking several nationwide registers. In Sweden, ethical approval is always required when using sensitive register data from authorities. The ethical vetting was performed by 'the Regional Ethical Review Board of Stockholm' (Original in Swedish: 'Regionala etikprövningsnämnden i Stockholm'), Sweden according to the Swedish Ethical Review Act and after that also by each of the three different authorities/data keepers (Statistics Sweden, the National Board of Health and Welfare, and the National Social Insurance Agency) according to the Public Access to Information and Secrecy Act, the Personal Data Act, and the Administrative Procedure Act. The Regional Ethical Review Board can waive the requirement to consult in these type of large register studies, and for this project stated that the consent to participate was not applicable. (Consent to participate: "Not applicable").

Consent for publication

Not applicable

\section{Competing interests}

The authors declare that they have no competing interests.

\section{Publisher's Note}

Springer Nature remains neutral with regard to jurisdictional claims in published maps and institutional affiliations.

\section{Author details}

'Department of Clinical Neuroscience, Division of Insurance Medicine, Karolinska Institutet, SE-171 77 Stockholm, Sweden. ${ }^{2}$ Department of Clinical Neuroscience, Division of Psychiatry, Karolinska Institutet, Karolinska University Hospital, Stockholm, Sweden. ${ }^{3}$ Department of Clinical Sciences, Division of Psychiatry, Umeå University, Umeå, Sweden. ${ }^{4}$ National Institute for Health and Welfare, Helsinki, Finland. ${ }^{5}$ Department of Analysis and Forecast, Swedish Social Insurance Agency, Stockholm, Sweden.

Received: 7 June 2017 Accepted: 1 February 2018

Published online: 13 February 2018

References

1. Järvisalo J, Anderson B, Boedeker W. Houtman I (eds.): mental disorders as a major challenge in prevention of work disability: experiences in FInland, Germany, the Netherlands and Sweden. Helsinki: Kela; 2005.

2. Alexanderson $\mathrm{K}$, Norlund A. Swedish council on technology assessment in health care (SBU). Chapter 1. Aim, background, key concepts, regulations, and current statistics. Scand J Pub Health Suppl. 2004;63:12-30.

3. Social Insurance in Figures 2015. In. Sweden: The Social Insurance Agency; 2015.

4. OECD: Sickness, Disability and Work: Breaking the Barriers. A synthesis of findings across OECD countries. In. Paris; 2010.

5. OECD. Sick on the job? Myths and realities about mental health and work. In. Paris: OECD Publishing; 2012.

6. OECD. Mental health and work: Sweden. Paris: OECD Publishing; 2013.

7. Adler DA, McLaughlin TJ, Rogers WH, Chang H, Lapitsky L, Lerner D. Job performance deficits due to depression. Am J Psychiatry. 2006;163(9):1569-76. 
8. Knudsen AK, Harvey SB, Mykletun A, Overland S. Common mental disorders and long-term sickness absence in a general working population. The Hordaland health study. Acta Psychiatr Scand. 2013;127(4):287-97.

9. Knudsen AK, Overland S, Aakvaag HF, Harvey SB, Hotopf M, Mykletun A. Common mental disorders and disability pension award: seven year followup of the HUSK study. J Psychosom Res. 2010;69(1):59-67.

10. Kupfer DJ, Frank E, Phillips ML. Major depressive disorder: new clinical, neurobiological, and treatment perspectives. Lancet. 2012;379(9820):1045-55.

11. Rhebergen D, Batelaan NM, de Graaf R, Nolen WA, Spijker J, Beekman AT, Penninx BW. The 7-year course of depression and anxiety in the general population. Acta Psychiatr Scand. 2011;123(4):297-306.

12. Simon GE, Barber C, Birnbaum HG, Frank RG, Greenberg PE, Rose RM, Wang PS, Kessler RC. Depression and work productivity: the comparative costs of treatment versus nontreatment. J Occup Environ Med. 2001;43(1):2-9.

13. Apfel T, Richer-Rossler A. Delay of diagnosis and treatment in psychiatric patients applying for a disability pension - a challenge for all of us. Swiss Med Wkly. 2008;138(23-24):348-54

14. Beck A, Crain LA, Solberg LI, Unutzer J, Maciosek MV, Whitebird RR, Rossom RC. The effect of depression treatment on work productivity. Am J Manag Care. 2014;20(8):e294-301.

15. OECD: Mental health, disability and work: issues for discussion. In. Paris; 2010.

16. Honkonen Tl, Aro TA, Isometsa ET, Virtanen EM, Katila HO. Quality of treatment and disability compensation in depression: comparison of 2 nationally representative samples with a 10-year interval in Finland. J Clin Psychiatry. 2007;68(12):1886-93.

17. Hartvig P. Untreated psychiatric disability. A study of disabled persons with major psychiatric health impairment, having never received psychiatric treatment. Scand J Soc Med. 1978;6(3):117-24.

18. Laaksonen M, Metsa-Simola N, Martikainen P, Pietilainen O, Rahkonen O, Gould R, Partonen T, Lahelma E. Trajectories of mental health before and after old-age and disability retirement: a register-based study on purchases of psychotropic drugs. Scand J Work Environ Health. 2012;38(5):409-17.

19. Leinonen T, Lahelma E, Martikainen P. Trajectories of antidepressant medication before and after retirement: the contribution of sociodemographic factors. Eur J Epidemiol. 2013;28(5):417-26.

20. Oksanen T, Vahtera J, Westerlund H, Pentti J, Sjosten N, Virtanen M, Kawachi I, Kivimaki M. Is retirement beneficial for mental health?: antidepressant use before and after retirement. Epidemiology (Cambridge, Mass). 2011;22(4):553-9.

21. Deverill C KM: Common Mental Disorders. In: Adult psychiatric morbidity in England. edn. Edited by McManus S MH, Brugha T, Bebbington $P_{\text {" }} \mathrm{R}$ J. London: The NHS Information Centre for health and social care; 2009: 25-27.

22. Koopmans PC, Bultmann U, Roelen CA, Hoedeman R, van der Klink JJ, Groothoff JW. Recurrence of sickness absence due to common mental disorders. Int Arch Occup Environ Health. 2011;84(2):193-201.

23. Rahman S, Alexanderson K, Jokinen J, Mittendorfer-Rutz E. Risk factors for suicidal behaviour in individuals on disability pension due to common mental disorders - a nationwide register-based prospective cohort study in Sweden. PLoS One. 2014;9(5):e98497.

24. Rahman SG, Alexanderson K, Jokinen J, Mittendorfer-Rutz E. Disability pension due to common mental disorders and subsequent suicidal behaviour: a population-based prospective cohort study. BMJ Open. 2016;6(4):e010152.

25. WHO: International Statistical Classification of Diseases and Related Health Problems, 10 revision (ICD 10). In.; 2010.

26. WHO Collaborating Centre for Drug Statistics Methodology (WHOCC). ATC/DDD Index 2016. http://www.whocc.no/atc_ddd_index/. Accessed 7 Feb 2016.

27. WHO Collaborating Centre for Drug Statistics Methodology. Definition and general consideration 2016. http://www.whocc.no/ddd/definition_and_ general_considera/. Accessed 7 Feb 2016.

28. Mutual Information System on Social Protection. Social protection in the Member States of the European Union (MISSOC), European Economic Area and Switzerland. http://www.missoc.org/MISSOC/INFORMATIONBASE/ COMPARATIVETABLES/MISSOCDATABASE/comparativeTableSearch.jsp. Accessed 1 June 2016

29. The Dental and Pharmaceutical Benefits Agency (Tandvård- och Läkemedelsförmånsverket) http://tlv.se/lakemedel/hogkostnadsskyddet/safungerar-hogkostnadsskyddet/. Accessed 1 June 2016.

30. Jones BL, Nagin DS, Roeder K. A SAS procedure based on mixture models for estimating developmental trajectories. Sociol Methods Res. 2001;29(3):374-93.

31. Cote S, Tremblay RE, Nagin D, Zoccolillo M, Vitaro F. The development of impulsivity, fearfulness, and helpfulness during childhood: patterns of consistency and change in the trajectories of boys and girls. J Child Psychol Psychiatry Allied Discip. 2002;43(5):609-18.
32. Jones BL. 'traj' group-based modeling of longitudinal data https://www andrew.cmu.edu/user/bjones/index.htm . Accessed 3 Feb 2016.

33. Quality and content of Patient registry. In. Sweden: The National Board of Health and Welfare; 2009.

34. Ludvigsson JF, Andersson E, Ekbom A, Feychting M, Kim JL, Reuterwall C, Heurgren M, Olausson PO. External review and validation of the Swedish national inpatient register. BMC Public Health. 2011;11:450.

35. Cause of Death 2014. In. Sweden: The National Board of Health and Welfare; 2015.

36. Ludvigsson JF, Almqvist C, Bonamy AK, Ljung R, Michaelsson K, Neovius M, Stephansson O, Ye W. Registers of the Swedish total population and their use in medical research. Eur J Epidemiol. 2016:31(2):125-36.

37. Wettermark B, Hammar N, Fored CM, Leimanis A, Otterblad Olausson P, Bergman U, Persson I, Sundstrom A, Westerholm B, Rosen M. The new Swedish prescribed drug register-opportunities for pharmacoepidemiological research and experience from the first six months. Pharmacoepidemiol Drug Saf. 2007;16(7):726-35.

38. Ljungdahl LO, Bjurulf $P$. The accordance of diagnoses in a computerized sick-leave register with doctor's certificates and medical records. Scand J Soc Med. 1991;19(3):148-53.

39. Shrivastava A, Johnston M, Bureau Y. Stigma of mental IIIness-1: clinical reflections. Mens Sana Monogr. 2012;10(1):70-84.

40. Lauber C. Stigma and discrimination against people with mental illness: a critical appraisal. Epidemiologia e Psichiatria Sociale. 2008;17(1):10-3.

41. Hensing G, Wahlstrom R. Swedish council on technology assessment in health care (SBU). Chapter 7. Sickness absence and psychiatric disorders. Scand J Pub Health Suppl. 2004;63:152-80.

42. Masand PS. Tolerability and adherence issues in antidepressant therapy. Clin Ther. 2003;25(8):2289-304.

43. David DJ, Gourion D. Antidepressant and tolerance: determinants and management of major side effects. L'Encephale. 2016;42(6):553-61.

44. Hung $\mathrm{Cl}$. Factors predicting adherence to antidepressant treatment. Curr Opin Psychiatry. 2014;27(5):344-9.

45. Trivedi MH, Morris DW, Wisniewski SR, Lesser I, Nierenberg AA, Daly E, Kurian BT, Gaynes BN, Balasubramani GK, Rush AJ. Increase in work productivity of depressed individuals with improvement in depressive symptom severity. Am J Psychiatry. 2013;170(6):633-41.

46. Hensing G, Bertilsson M, Ahlborg G, Jr., Waern M, Vaez M: Self-assessed mental health problems and work capacity as determinants of return to work: a prospective general population-based study of individuals with allcause sickness absence. BMC Psychiatry 2013, 13:259.

47. Bertilsson M, Love J, Ahlborg G, Jr., Hensing G: Health care professionals' experience-based understanding of individuals' capacity to work while depressed and anxious. Scand J Occup Ther 2015, 22(2):126-136.

48. Clark A, Postel-Vinay F. Job security and job protection. Oxf Econ Pap. 2009; 61(2):207-39.

49. Kessler RC, Berglund P, Demler O, Jin R, Merikangas KR, Walters EE. Lifetime prevalence and age-of-onset distributions of DSM-IV disorders in the National Comorbidity Survey Replication. Arch Gen Psychiatry. 2005;62(6):593-602.

50. Copeland WE, Angold A, Shanahan L, Costello EJ. Longitudinal patterns of anxiety from childhood to adulthood: the great Smoky Mountains study. J Am Acad Child Adolesc Psychiatry. 2014;53(1):21-33.

51. Merikangas KR, He JP, Burstein M, Swanson SA, Avenevoli S, Cui L, Benjet C, Georgiades K, Swendsen J. Lifetime prevalence of mental disorders in U.S. adolescents: results from the National Comorbidity Survey ReplicationAdolescent Supplement (NCS-A). J Am Acad Child Adolesc Psychiatry. 2010; 49(10):980-9.

52. Eisenberg D, Golberstein E, Gollust SE. Help-seeking and access to mental health care in a university student population. Med Care. 2007;45(7):594-601.

53. Burns BJ, Ryan Wagner H, Gaynes BN, Wells KB, Schulberg HC. General medical and specialty mental health service use for major depression. Int J Psychiatry Med. 2000;30(2):127-43.

54. Skaner Y, Nilsson GH, Arrelov B, Lindholm C, Hinas E, Wilteus AL, Alexanderson K. Use and usefulness of guidelines for sickness certification: results from a national survey of all general practitioners in Sweden. BMJ Open. 2011;1(2):e000303.

55. Mittendorfer-Rutz E, Alexanderson K, Kjeldgård L, Wikman A. Sjukskrivning och risk för framtida sjuk- och aktivitetsersättning bland kvinnor och män [Report in Swedish]. Sickness absence and risk for future Disability pension among women and men [Translation]. Stockholm. Division of Insurance Medicine, Deaprtment of Clinical Neurosciencew, Karolinska Institutet. http://ki.se/sites/ default/files/delrapport_3_hela_1.pdf. Accessed 23 Dec 2017. 